Vol. 4, No. 1, Maret 2020, Hal. 70-76

\title{
INTRODUCING INVESTMENT CULTURE THROUGH CAPITAL MARKET
}

\author{
Tine Badriatin $^{1^{*}}$, Lucky Radi Rinandiyana ${ }^{2}$, Sri Sudiarti ${ }^{3}$, Asep Saepudin ${ }^{4}$ \\ ${ }^{1}$ Prodi Keuangan dan Perbankan, Universitas Siliwangi, Indonesia \\ ${ }^{2}$ Prodi Manajemen, Universitas Siliwangi, Indonesia \\ ${ }^{3}$ Prodi Manajemen Perusahaan, Politeknik Triguna, Indonesia \\ ${ }^{4}$ Prodi Manajemen, Universitas Langlang Buana, Indonesia \\ tinebadriatin@gmail.com, ${ }^{2}$ luckyradi@unsil.ac.id, ${ }^{3}$ srisudiarti485@gmail.com, \\ asep.saepudin@unla.ac.id
}

\begin{abstract}
ABSTRAK
Abstrak: Pengenalan pasar modal pada kalangan generasi muda khususnya bagi mahasiswa baru dalam meningkatkan literasi dan inklusi keuangan untuk meningkatkan pengetahuan dalam berinvestasi maka kegiatan ini dilaksanakan melalui metode seminar dengan jumlah peserta sebanyak 150 orang mahasiswa tingkat 3, dimana harapannya dengan adanya kegiatan ini mahasiswa dapat lebih mengenal budaya investasi dengan mengubah paradigma dari saving society menjadi investing society. Kegiatan ini belum begitu mendapatkan hasil yang optimal dalam hal kesadaran berinvestasi di pasar modal sehingga masih diperlukan pembelajaran dan pelatihan secara berkelanjutan dimana hal ini ditandai dengan hanya 5 orang peserta yang tertarik untuk membuka rekening efek, Namun secara pengetahuan dari mereka sudah bertambah luas dimana lembar pertanyaan yang diberikan kepada peserta mengenai pengenalan pasar modal yang disampaikan dapat terisi dengan baik dan benar.
\end{abstract}

Kata kunci: Literasi; Inklusi keuangan; Pasar modal

Abstract: The introduction of the capital market among young people, especially for new students in increasing financial literacy and inclusion to increase knowledge in investing, this activity was carried out through a seminar method with a total of 150 students level 3, where the hope was that with this activity students could get to know investment culture by changing the paradigm from saving society to investing society. This activity did not yet get optimal results in terms of awareness of investing in the capital market so that it was still needed continuous learning and training where it was marked by only 5 participants who were interested in opening a securities account, but the knowledge from them had expanded where the question sheets given to participants regarding the introduction of capital markets which can be filled properly and correctly.

Keywords: Literacy; Inclusion; Capital market

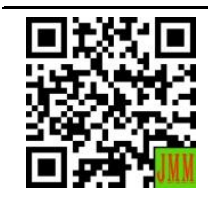

Article History:

Received: 31-01-2020

Revised : 20-02-2020

Accepted: 24-02-2020

Online : 03-03-2020

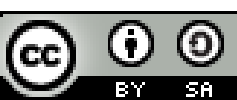

This is an open access article under the $C C-B Y-S A$ license 


\section{A. LATAR BELAKANG}

Bagi kalangan muda tentunya mengenal kata investasi bukanlah hal yang asing, karena pada dasarnya investasi merupakan suatu kegiatan dengan menanamkan modal pada suatu perusahaan atau aset dimana bertujuan agar dimasa yang akan datang diperoleh keuntungan yang berlipat (Tandelilin, 2010), (Gumanti \& Ary, 2011). Maka tidaklah heran jika asumsi sebagian besar masyarakat menilai bahwa investasi hanyalah milik orang-orang yang berpenghasilan tinggi, namun anggapan itu harus diluruskan. Oleh karena itu pengetahuan tentang investasi harus dikenalkan sejak dini untuk mengubah paradigma dan kebiasaan dari investasi itu hanya menabung saja menjadi gerakan investasi dari saving society menjadi investing society (Badriatin, 2019). Dengan kata lain menyimpan dalam bentuk deposito nilainya semakin lama semakin turun seiring dengan pertumbuhan inflasi (Otoritas Jasa Keuangan, 2018).

Salah satu bentuk investasi tersebut adalah dengan mengenalkan pasar modal dimana pasar modal merupakan salah satu sumber pendanaan (Faozan, 2013). Belajar pasar modal tidaklah sesulit yang diperkirakan sebagian besar masyarakat umum, investasi di pasar modal sangatlah mudah (Hasibuan, 2018). Memang pada kenyatannya generasi milenial masih belum banyak yang mengetahui dengan kata investasi karena masih memilih untuk bergaya hidup yang tinggi seperti belanja, nongkrong di kafe dibandingkan dengan harus menyisihkan sebagian uangnya untuk mulai belajar investasi. Padahal untuk saat ini investasi di pasar modal hanya cukup dengan Rp. 100 ribu saja mereka sudah dapat memulai berinvestasi. Jadi kegiatan ini juga untuk memberikan informasi buat mahasiswa agar melek informasi mengenai bagaimana caranya berinvestasi di pasar modal (Otoritas Jasa Keuangan, 2018) sehingga menciptakan investor baru di pasar modal dimana sebagai generasi muda nantinya mampu melindungi aset-aset bangsa (Willem, 2018). Dalam berinvestasi informasi sangat dibutuhkan para calon investor untuk mengurangi ketidakpastian dalam membuat keputusan berinvestasi (Pasaribu, 2016).

Sejauh ini masyarakat hanya memandang bahwa investasi di pasar modal itu sangatlah mahal sehingga tidak mungkin akan terjangkau oleh masyarakat luas. Maka sebagai mahasiswa yang menjadi cikal bakal dalam kehidupan bermasyarakat tentunya harus diberi pembekalan pengetahuan dalam hal ini budaya berinvestasi sehingga nantinya sudah siap dalam berkontribusi kepada masyarakat dimana investasi itu khususnya pasar modal dapat dijadikan salah satu bentuk dalam berinvestasi. Jadi mengubah asumsi bahwa pasar modal hanyalah milik orang kaya yang berkantung tebal serta memusingkan (Gregoriou, 2016).

Untuk itu tujuan dari kegiatan ini adalah mengenalkan budaya investasi sejak dini kepada para generasi muda melalui pasar modal. Namun demikian minat investasi juga dipengaruhi oleh beberapa faktor antara lain ketersediaan sarana dan prasana, SDM, Sosialisasi dan Pelatihan, Harga minimal investasi (Bakhri, 2018). Mengenalkan peran penting bagi perekonomian suatu negara dengan pasar modal.

Selain itu berdasarkan kegiatan sebelumnya kepada mahasiswa baru Triguna bahwa seminar pasar modal ini juga bertujuan untuk menanamkan jiwa berinvestasi agar generasi muda tidak mudah tergiur 
dengan beragam investasi yang bodong yang sedang marak sekarang ini serta lebih siap menghadapi masa depan dengan kesiapan finansial (Badriatin, 2020). Kegiatan ini merupakan kegiatan yang kedua kalinya dimana sebelumnya pernah dilakukan seminar pasar modal dengan peserta mahasiswa baru Poltek Triguna namun pada kegiatan sebelumnya hanya dilaksanakan melalui seminar pasar modal saja dimana hasilnya para mahasiswa masih belum memberikan kesadaran untuk mulai mencoba berinvestasi di pasar modal tetapi menambah kemampuan berfikir kritis peserta akan budaya investasi (Hermuningsih \& Wardani, 2016). Oleh karena itu selain memberikan edukasi dan informasi yang benar mengenai mekanisme menjadi investor saham mahasiswa dapat memahami sehingga dapat melakukan sendiri bagaimana cara mekanisme perdagangan di pasar modal.

\section{B. METODE PELAKSANAAN}

Pelaksanaan kegiatan ini menggunakan metode seminar dan tanya jawab. Seminar secara terminology merupakan kegiatan yang dilakukan oleh seorang ahli / peneliti untuk menyampaikan atau mempresentasikan suatu karya ilmiah kepada para peserta, yang berguna dalam hal membantu mengambil keputusan. Menurut Kasirom (2010) seminar merupakan kegiatan yang dilakukan sebagai proses untuk memecahkan suatu masalah, atau proses menemukan solusi yang biasanya diangkat dari hasil sebuah penelitian / literature .

Seminar kegiatan ini dilaksanakan di Kampus Politeknik Triguna dengan jumlah peserta sebanyak 150 mahasiswa tingkat 3 bertempat di Aula Poltek Triguna Tasikmalaya. Dimana Materi yang diberikan oleh praktisi pasar modal dari PT. Reliance Sekuritas Indonesia, Tbk Kantor Perwakilan Tasikmalaya bersama GIBEI Fakultas Ekonomi Universitas Siliwangi RELI Divisi Pendidikan dan Pelatihan. Kemudian dilanjutkan dengan tanya jawab dan sharing session dengan KSPM Universitas Siliwangi untuk dapat berbagi pengalaman seputar investasi di pasar modal yang dapat dilakukan oleh generasi muda yang dalam kegiatan ini sasarannya adalah mahasiswa perguruan tinggi. Metode Tanya jawab menurut Widayati (2012) merupakan cara penyajian pelajaran dalam bentuk pertanyaan dimana diperlukan jawaban, terutama oleh narasumber atau pemateri kepada audience, tapi dapat pula dari audience kepada narasumber atau pemateri

Acara ini ditutup dengan pemberian cendera mata kepada penanya terbaik serta penutupan. Di akhir sesi peserta yang akan mulai mencoba menjadi calon investor difasilitasi oleh sekuritas untuk dapat membuka opening account agar dapat memulai investasi di pasar modal. Opening account ini merupakan salah satu persyaratan bagi calon investor yang akan memulai berinvestasi di pasar modal dengan melengkapi persyaratan pembukaan rekening, dimana sebelum melakukan investasi di pasar modal para calon investor harus membuka rekening efek terlebih dahului melalui sekuritas sehingga nantinya diperoleh rekening transaksi (Reliance 
Indonesia, 2017). Lebih rinci alur kegiatan seminar ini seperti terlihat dalam Gambar 1 berikut:

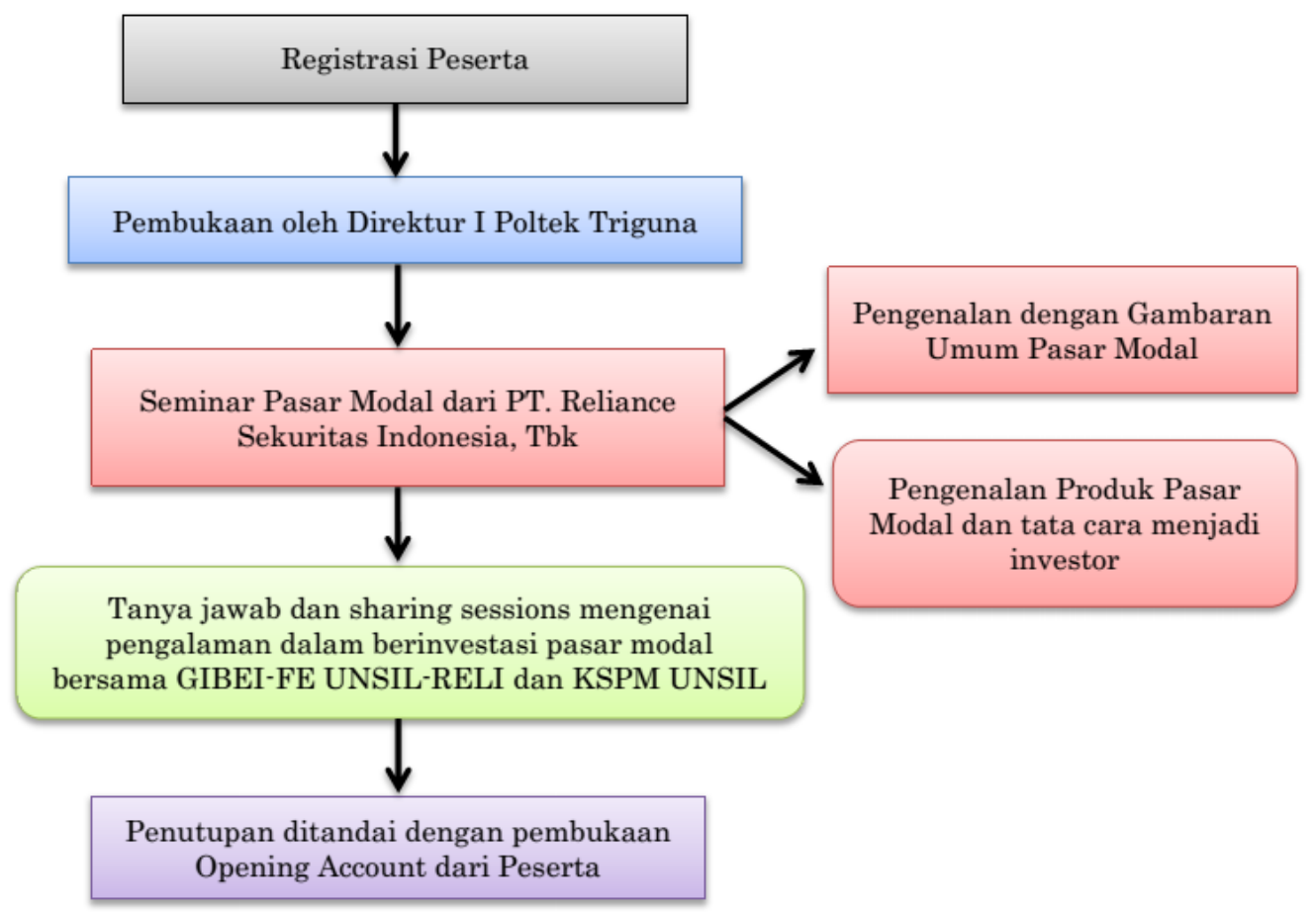

Gambar 1. Alur kegiatan Seminar Mengenalkan Budaya Investasi

\section{HASIL DAN PEMBAHASAN}

Dalam pelaksanaan kegiatan ini melibatkan praktisi dari PT. Reliance Sekuritas Indonesia, Tbk Kantor Perwakilan Tasikmalaya sebagai salah satu anggota Bursa untuk menjadi narasumber, selain itu juga dari Divisi Pendidikan dan Pelatihan GIBEI FE UNSIL - RELI Universitas Siliwangi.

Sebelum melaksanakan kegiatan seminar pasar modal peserta melakukan registrasi terlebih dahulu dimana beberapa dari peserta yang sudah berminat untuk membuka rekening sendiri mengumpulkan beberapa persyaratan dalam pembukaan rekening saham.

Seminar dilaksanakan dalam dua sesi yaitu dari kalangan praktisi dan GIBEI-FE UNSIL-RELI dengan mengundang Kelompok Studi Pasar Modal dari Universitas Siliwangi sebagai sharing sesion dalam pengalaman berinvestasi di kalangan mahasiswa.

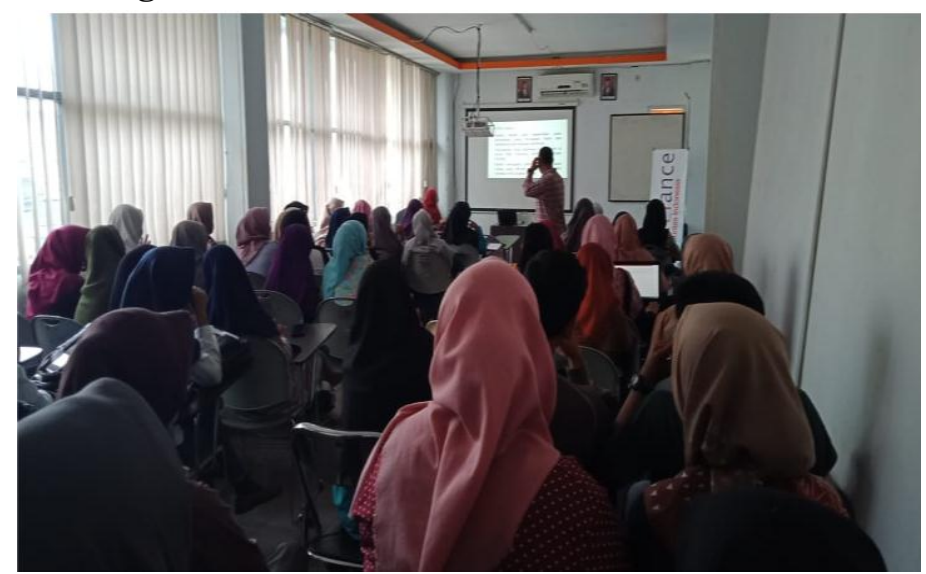

Gambar 2. Peserta Seminar Pasar Modal 
Materi yang diberikan dalam pelaksanaan seminar ini adalah gambaran umum mengenai pasar modal dan pengenalan produk serta tata cara menjadi investor, dimana untuk menjadi investor pasar modal para calon investor harus mempunyai rekening efek terlebih dahulu. Untuk mempunyai rekening efek cukup dengan melampirkan persyaratan pembukaan rekening seperti pengisian form pembukaan rekening, Photocopy KTP, Photocopy NPWP jika ada, Photocopy cover tabungan atas nama pemilik rekening.

Setelah dilaksanakan seminar dan tanya jawab kegiatan ini dilanjutkan dengan sharing session dengan KSPM Universitas Siliwangi dimana mereka akan berbagi pengalaman seputar investasi di pasar modal. Tujuan sharing sessions ini tidak lain sebagai gambaran dan mengubah paradigma bahwa berinvestasi itu harus kaya dan berduit. Namun pada kenyataannya generasi muda pun bisa memulai untuk dapat berinvestasi.

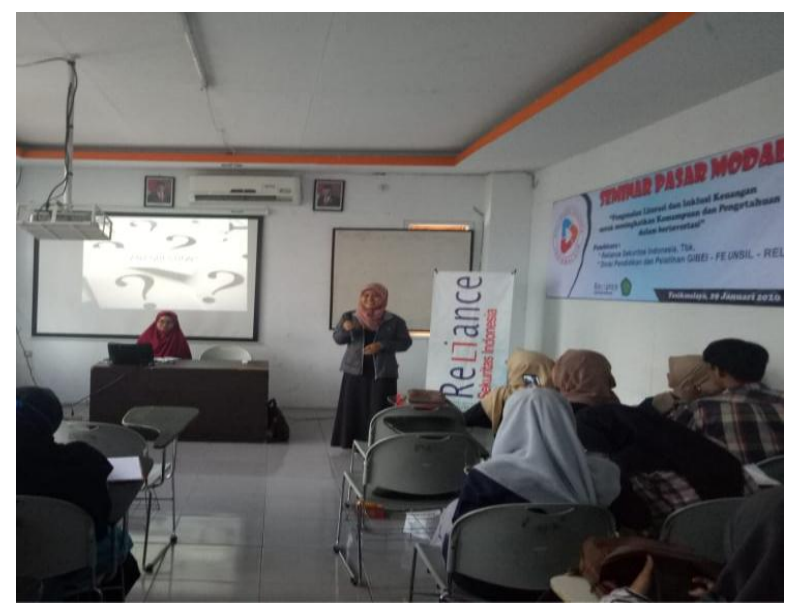

Gambar 3. Sharing Sessions

Kegiatan ditutup dengan pembukaan rekening efek bagi mereka yang akan mulai mencoba berinvestasi di pasar modal. Berdasarkan hasil pelaksanaan pengabdian ini terlihat bahwa para peserta sangat antusias mengikuti penyampaian materi dan sharing sessions. Hal ini terbukti dengan $90 \%$ mahasiswa dapat melakukan pengisian form investasi.

\section{SIMPULAN DAN SARAN}

Kegiatan ini menghasilkan kesimpulan yaitu Mahasiswa tingkat 3 Poltek Triguna Tasikmalaya menjadi bertambah pengetahuannya mengenai investasi khususnya pasar modal hal ini ditandai dengan hampir 90\% mahasiswa dapat mengisi form yang dibagikan mengenai gambaran umum pasar modal, mulainya berfikir mengenai bagaimana menanamkan budaya investasi sejak dini dimana hal ini ditandai dengan adanya beberapa mahasiswa yang sudah tertarik belajar berinvestasi khususnya bidang pasar modal dengan mencoba mendaftar menjadi calon investor hal ini terlihat dengan adanya pengumpulan berkas yang menjadi persyaratan menjadi seorang investor di Bursa Efek Indonesia melalui sekuritas 
terdekat. Selain itu terbentuknya kerja sama antara pihak perguruan tinggi dan sekuritas untuk bersama-sama memasyarakatkan serta mengedukasikan pasar modal sebagai salah satu alternative investasi selain menabung, serta menjadikan peluang bagi mahasiswa khususnya tingkat akhir yang akan mengikuti magang untuk dapat melihat serta terjun secara langsung bagaimana kegiatan di pasar modal yang selama ini hanya sebatas teori di kelas saja. Namun demikian kegiatan ini diperlukan keberlanjutan karena seiring perkembangannya pasar modal sangatlah dinamis serta perlu pemahaman yang tepat untuk dapat berinvestasi agar tidak salah dalam memilih saham untuk diinvestasikan.

\section{UCAPAN TERIMA KASIH}

Penulis mengucapkan terima kasih kepada LPPM Politeknik Triguna Kota Tasikmalaya yang telah memfasilitasi dalam mengadakan kegiatan literasi dan inklusi Pasar Modal. Selanjutnya, kepada PT. Reliance Sekuritas Indonesia, Tbk Kantor Perwakilan Tasikmalaya yang telah bersedia menjadi narasumber serta memberikan kontribusinya dalam kegiatan ini. Tak lupa penulis juga mengucapkan terima kasih kepada GIBEI FE UNSIL RELI khususnya Divisi Pendidikan dan Pelatihan serta KSPM Universitas Siliwangi yang sudah banyak membantu pelaksanaan kegiatan ini.

\section{DAFTAR RUJUKAN}

Badriatin, T., Radi Rinandiyana, L., \& Sudiarti, S. (2020). Pelatihan Investasi Sejak Dini Melalui Pasar Modal Pada Mahasiswa Baru Politeknik Triguna Tasikmalaya. JCES (Journal of Character Education Society), 3(1), 8-16.

Badriatin, T., Radi Rinandiyana, L., Waliyul Mujtahidin, F., \& istiana Mulyani, E. (2019). Capital Market Literation Program In Class. JCES (Journal of Character Education Society), 2(1), 24-29.

Bakhri, S. (2018). Minat Mahasiswa Dalam Investasi Di Pasar Modal. Al-Amwal: Jurnal Ekonomi Dan Perbankan Syari'ah, 10(1), 146. https://doi.org/10.24235/amwal.v10i1.2846

Faozan, A. (2013). Konsep Pasar Modal Syariah. Muqtasid: Jurnal Ekonomi Dan Perbankan Syariah, 4(2), 287. https://doi.org/10.18326/muqtasid.v4i2.287-310

Gregoriou, A. (2016). A simple behavioural model of investor holding periods under the presence of trading costs. Applied Economics Letters, 23(6), 432-435. https://doi.org/10.1080/13504851.2015.1080795

Gumanti, \& Ary, T. (2011). Manajemen Investasi: Konsep, Teori, dan Aplikasi. Jakarta: Mitra Wacana Media. https://doi.org/10.1163/_q3_SIM_00374

Hasibuan, S. R. (2018). Minat Investasi Mahasiswa Untuk Berinvestasi di Pasar Modal Syariah (Studi Kasus di Galeri Investasi Syariah UIN Sumatera Utara Periode 2017- 2018). Skripsi Universitas Islam Negeri Sumatera Utara Medan.

Hermuningsih, S., \& Wardani, K. (2016). Metode Online Stock Trading Sebagai Literasi Dalam Pengembangan Model Pembelajaran Mata Kuliah Pasar Modal. Seminar Nasional Sistem Informasi Indonesia (SESINDO), 2016(November), 309-316.

Indonesia, R. S. (2017). Equity (Brokerage). WWw.reliancesekuritas.com.

Kasirom, M. (2010). Metodologi Penelitian Kuantitatif-Kualitatif. In Malang: UIN Maliki Press (p. 257).

Otoritas Jasa Keuangan. (2018). Kata Siapa Buka Rekening Saham itu Susah? 
76 | JMM (Jurnal Masyarakat Mandiri) | Vol. 4, No. 1, Maret 2020, hal. 70-76

Baca Artikel Berikut Ini Untuk Tahu Lebih Lanjut! Https.//sikapiuangmu.ojk.go.id.

Pasaribu, Y. (2016). Reaksi Pasar Terhadap Pengumuman Stock Split Dan Reverse Stock Split Pada Perusahaan Yang Terdaftar Di Bursa Efek Indonesia. Jurnal Manajemen Update, 6(1).

Willem, JF., et al. (2018). Pkm Literasi Dan Inklusi Berinvestasi Di Pasar Modal

Bagi Investor Pemula Kelompok Studi Kspm E-Stoc, Kota Manado, Provinsi Sulawesi Utara. (2018). Jurnal Berkala Ilmiah Efisiensi, 18(4).

Tandelilin, E. (2010). Dasar-dasar Manajemen Investasi. Keuangan, 34.

Widayati, A. (2012). Metode Mengajar Sebagai Strategi Dalam Mencapai Tujuan

Belajar Mengajar. Jurnal Pendidikan Akuntansi Indonesia, 3(1). https://doi.org/10.21831/jpai.v3i1.836 